\title{
D. RAFAEL JOSÉ DE CRESPO. EPÍGONO DEL XVIII
}

I. Don Rafael José de Crespo (1779-1842) sigue siendo un escritor por descubrir. Si hay algunos trabajos sobre su narrativa, 'mucho queda por hacer en cuanto a su obra poética respecta.

La producción en verso del poeta de Alfajarín, aunque escasa, ${ }^{2}$ abarca un campo temático muy amplio. Él mismo nunca la quiso dar a luz porque consideraba la literatura como una diversión, un pasatiempo. ${ }^{3}$ Quizás, dada su condición de magistrado e Individuo del Consejo de Su Majestad, veía la poesía, igual que Jovellanos, ${ }^{1}$ como algo poco digno de un hombre serio.

Hace poco incluía yo a Rafael José de Crespo en la nómina de los poetas anacreónticos del Setecientos. ${ }^{5}$ Nace el escritor aragonés en Alfajarín, cerca de

1 Vid Josi Curfos MAINER. Rafart Jose de Grespo (1779-18+2) o al rpiganos en VV.AA.

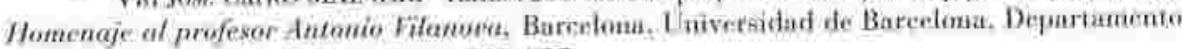
तe Filutogín cepaunola, 1989, 1, 11, pp, 335-3557.

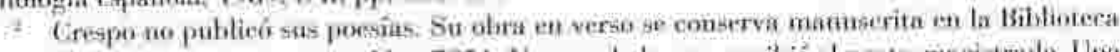
Nacional (Mastrid) con la sigmatura Msa, 7851. No es todes lo que escribió el poota-magistrado. Una

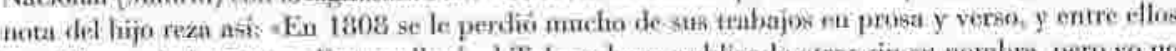

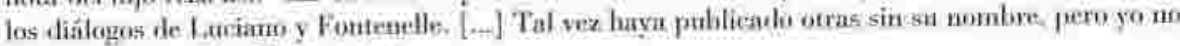

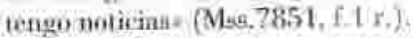

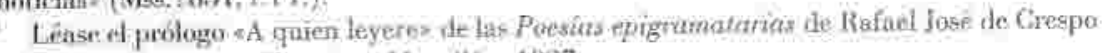
publicidas en Zuraguza por Francisco Magallöri, 1827

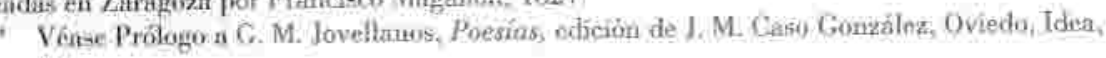
$1961 ;$, 90

5 Mbol Nang, La poesia anacréntica en España en et s. XVHI, Madrid, Universidad Complutense, 1990 Tesis doctoral, t. I, págs. 577-581. 
Zaragoza, en 1779. Sus Fábulas morales y literarias, ${ }^{6}$ que consideraba como primeros ensayos de poesia porque escritas en tierna edad, deberían haberlo sido antes de 1809, año que marca, desde ol punto de vista literario, el fin del siglo XVIII. El modelo es incomirstublemente el cunario T'umsas de Iriarte. Las anacreónticas, género muy popular en la España do las Luces, constituyen un $44 \%$ de sus versos. En su Poética de 1839, los primeros modelos que cita Rafael José de Crespo son

\section{...Meléndez [Vuldéz] el de las alas sonorn.s \\ $Y$ a Moratín el ingenioso en sales.}

Fs archisabida la influencia que ejercieron el magistrado extremeño y cl abogado madrileño en la lírica española del Siglo Ilustrado.?

Muchos de los trabajos do Crespo se perdieron en 1808. ${ }^{10}$ No se sabes pues, con exactitud, cuánto salió de su pluma. Muchos poemas del manuserito Mss. 7851 que conserva la Biblioteca Nacional no llevan la fecha de composición. Algunos, en cambios catán fochados y permiten extender la producción del antoo de Crespo lasta 1830.

\section{Modelos}

La originalidad en el Setecientos no preocupaba a los poetas porque lo que más importaba era seguir a los poetas de renombre. Ėl Siglo Ilustrado es menos anhelante de singularidades. ${ }^{11}$ Fis un siglo racional, y siendo la razón esencialmente universalista, asomarán en el horizonte conceptos que sitúan al hombre

" Rafael ,osć DL (:RP.SPO, Fábulks morales y literaras pur leyes en la Universidad literaria de Zaragoza, Zaragoza, Imprents de Luis Cone...., cacedrático de

I lem, pág. 4.

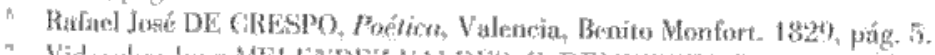

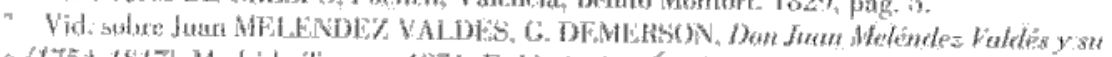

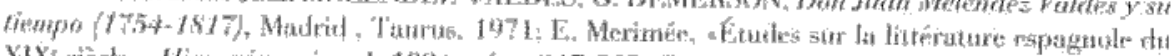

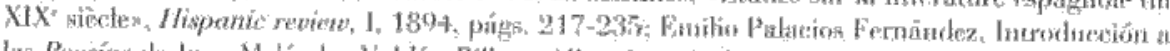

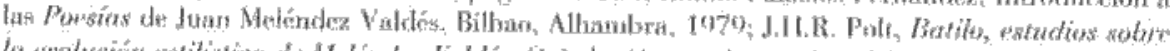

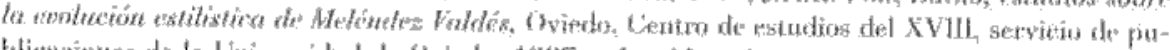

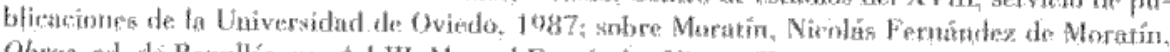

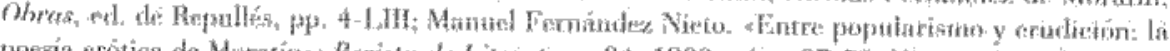

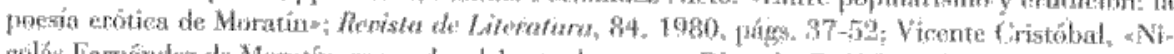

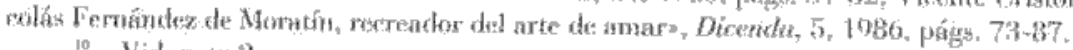

10 Vid. netid 2 . pág. 236.

11. Cartos BOUSONO PRIETO, Teoria de la expresión poétice, Madricl, Gredos, 1976, t. II, 
en su dimensión social, colectiva, inchuso en el campo de la literatura. Estamos en una época que no busca la gran novedad, sino la gran perfección, entendiendo esa última palabra en sentido racionalista. Había que imitar, pues, a los grandes maestros; e imitar es lo opuesto de innovar. La literatura vive en las cercanías de lo ya hecho. Parecería curioso que un siglo immovador en ideas no lo haya sido en el campo de las letras. Ello se debe esencialmente a lo que Carlos Bousoño Prieto llama «Procedimientos y modificantes extrínsecos propios de cualquier época». ${ }^{12}$ El Neoclasicismo en estética no es revolucionario:

- En mis poesías agradables - dice Juan Mcléndez Valdéf- lae procurado imitar a la naturaleza y hermosearla, siguiendo las huellas de la docta antigüedad, donde vemos a cada paso tán bellas y acnhadas imágenes $[\ldots]^{13}$

Las mismas ideas están en Trigueros, ${ }^{1+}$ y en Rafael José de Crespo:

«[... ] No sólo me he valido de argumentos ajenos, sino que también he procurado imitar a los mejores fabulistas. ${ }^{15}$

Y se pregunta: ¿Cuántos serían autores a no serlo otros antes? ${ }^{16}$

Como si fuera poco, confiesa haber imitado a Samaniego, La Fontaine, Horacio, Esopo, Argensola, y afirma que el modelo de sus fábulas es el canario Tomás de Iriarte. ${ }^{17}$ Cervantes es el modelo de Don Papis. Marcial, el de las Poesías epigramatarias. Támbién influyen en Crespo, el coronel José Cadalso ${ }^{18}$ y los clásicos que cita en su Poética.

Don Rafael José de Crespo dominaba el latín y el francés. Se conoce la influencia que tuvo el francés en las letras hispanas del siglo XVIII. El conocimiento del francés le puso en contacte con las obras de Jean Baptiste Rousseau, ${ }^{19}$ Boileau, Molière, Voltaire, La Mottte -buen imitador de los griegos y especialmente Anacreonte-, Racine.

Sería tarea de nunca acabar el ir señalando las lecturas e influencia que encontramos en el escritor aragonés. Su Poética, escrita en impecables tercetos de versos endecasílabos (único metro de todo el libro), es buena

12 Idem. págs. 85 y ss.

13 BAE, LXIII, pág. 87.

14 Cándido María DE TRIGUEROS, * Carta al editor* en El poeta filósofo, f.r/v

Is Rafael José DE CRESPO, Fábulas morales y literarias, ed. cit., pág. 6.

16 Idem., pág. 7.

17 Idem., págs. 8 y 9

18 Vid., José Carlos MAINER, art. cit, pág. 337.

19 La cantata "Circe*, Mss. 7851, f. 39 r, es una traducción de Juan Bautista Rousseau. 
muestra de su admiración por Garcilaso. En el libro muchos poetas defienden los géneros que cultivaron. ${ }^{20}$ Luego desfilan ante nosotros Virgilio, Juan Meléndez Valdés, Moratín padre, Iriarte, Mena, Horacio, Homero, Catulo, Tibulo, Lucrecio, Rioja, Anacreonte, Herrera, Píndaro, Cicerón, Guttemberg, Tasso, Lucano, Eurípides, Sófocles, Milton, Milière, Quevedo, Séneca, Fray Luis de León, Teócrito, Gesner, St. Lambert, Racine, La Fontaine, Boileau, Juvenal.

La lectura de la Poética lleva a afirmar, sin riesgo de equivocarse, que Rafael José de Crespo fue, un buen ilustrado, un hombre de una vasta erudición. Leyó sobre todo a los clásicos griegos y latinos, a los franceses y a los poetas españoles del Setecientos. ${ }^{21}$ De esas diferentes lecturas sacaba el vate aragonés el jugo para las composiciones propias. Era consciente de que estaba imitando, pero en el sentido que tenía la palabra en eI XVIII: estímulo, emulación. Ya estamos en los laberintos de "La Biblioteca de babel" del argentino Jorge Luis Borges. ${ }^{22}$

\section{Géneros literarios}

La historia y la historia de la literatura se dan la mano. A la gran división de la historia en siglos, corresponde en la historia de la literatura la división en corrientes y escuelas literarias. La mentalidad de una época obedece necesariamente a lo que Carlos Bousoño llama la ley del asentimiento ${ }^{24}$ porque cada época constituye un modificante extrínseco de la literatura.

El manuscrito $7851^{24}$ de la Biblioteca Nacional se compone, entre otros, de géneros muy al uso en la España de la Ilustración. Recorrámoslo, pues, prestando especial atención a los géneros poéticos más cultivados por los neoclásicos dieciochescos.

ni Rafael José DE CRESPO, Poética, Valencia, Bernito Monfort, 1839. Léase todo el Ganto I.

21 Las notas puesta a pie de página del mss. 7851 lo confirman. Véase par ejemplo la nota 1, f. $344 \mathrm{r}$.

22 Véase «La Biblioteca de Babel s de Jorge Luis Borges, Ficciones, Madrid, Alianza Editorial, 1971, pág. 8. Para el escritor argentino, la literatura no es propiedad de nadie. Una obra puede inspirar otra, otra, y otras, indefinidamente, Por ello habla de catálogos de catálogos.

23 Carlos BOUSOÑO PRIETO, ob. cit., Il, págs. 34-48.

24 Sólo estudiaré los géneros más relacionados con el Setecientos. El volumen de las Poesías manuscritas de Crespo se componen de idilios, cantatas, cantinelas, romances, odas, epístolas, una égloga, un ditirambo, la traducción del Arte poética y de 30 odas de Horacio, 2 poemas heroicos, 3 tragedias y un conjunto de 31 poesías ligeras. 
Constituyen más del $45 \%$ de la producción en verso del poeta-magistrado. Es un conjunto de 31 poesías graciosas donde se notan claramente inspiración, espontaneidad en el versificar, facilidad en describir, maestría, profesión de fe anacreóntica, dado que Rafael José de Crespo imita con gracia a Anacreonte. $\mathrm{Es}$, sin duda alguna, el último vate dieciochesco rimador de dulces anacreónticas: “Mis deseos», «De la vida del hombre», «El niño de Cupido», «Sobre la vida sin cuidado», «A la tórtola», «De la vendimia», «De la filosofía», "De mí mismo», «Del oro», «Del poder de Baco», «Del vino», «A la muerte de la paloma de Egle» (que es una imitación del «Lutus in morte passeris» de Catulo) son piezas que aceptaría el mismo Anacreonte.

El poeta de Alfajarín escribió 14 cantinelas en 1808. Destacan *A la alba", "Danza en la mañana de San Juan», «Del café», "Inestabilidad de las cosas humanas», "Contra la adustez filosófica», «Del otoño», «De las caricias», "A la noche», "A Egle», "A Naïs presentándole una guirnalda». Recogen los temas de la poesía ligera del vate teyo. La cantinela VI, que aconseja sobriedad y sabiduría a los viejos, es imitación de Haris, poeta anacreóntico persa.

Desgraciadamente, esas poesías siguen estando inéditas; lo que hace que se desconozca una de las mejores últimas colecciones anacreónticas de España.

\section{III-2. El Ditirambo a Baco}

Entra en la misma línea temático-estilística de las anacreónticas. La musa es Baco. El poema, mezcla de pentasílabos, ${ }^{25}$ heptasílabos, octosílabos, endecasílabos y dodecasílabos, desarrolla el anacreóntico tema báquico. Recuerda mucho la anacreóntica « ¿Quién es aquel que baja...?» del gaditano José Cadalso.

\section{III-3. Odas y romances}

De entrada hay que distinguir las propias y las traducciones de Horacio. Las 20 odas del vate aragonés son dieciochescas en cuanto al tema y metro se refiere. Recuérdese que la mayor parte de las poesías ligeras de Juan Meléndez Valdés la constituyen odas anacreónticas.

25 Es el metro más corto que encontramos en las anacreónticas dieciochescas. Lo utilizó N. F. Moratín en «El nido de amor*, «El sueño», "La barquilla», *Amor aldeano*, «Grato recuerdo», "Disculpa de un error», o sea, en un 23,4 \% de su producción anacreóntica. 
Ahora bien, las odas de Crespo abarean un campo temático amplio. «Los placeres del campos son una apología del mundo natural, lugar idóneo para la paz, la alegría, la pureza, la amistad, el amor, la bondad, la virtud, los placeres, el r'eposo. También las odas le sirven al poeta para meditar sobre Dios, el transcurso del tiempo, la muerte, la inmortalidad. «A la ruina de Zaragoza» y la «Oda por la feliz exaltación al trono del rey nuestro señor D. Fernando VII» son cantos épicos, "Consejos a Rosana" recuerda mucho a Ronsard de los Amours. Deben leerse con interés los siguientes poemas: «A la posteridad», «Inmortalidad del alma humana», "El poder del Cristianismo», «La aparición del rey San Fernando».

Al lado de esas odas, hay 30 otras de Horacio, traducidas en Valencia entre el 2 de mayo de 1835 y el 17 de junio del mismo año. Las encabeza la «Epístola de Horacio a los pisones sobre el arte poética, traducida al castellano en igual número de versos», obra llevada a cabo en Valencia desde el 18 de abril de 1835 hasta el $1 .^{\circ}$ del siguiente mayo. ${ }^{26}$ En «A quien leyere» se dan las razones que motivaron la traducción.

Nuestro estudio sería incompleto si no señaláramos otros tipos de odas como «A la rautividad de Babilonia», «I $\mathrm{La}$ ruina de Nínive», aCántico de David, ya libre de las asechanzas de Saúl», «Cántico elegíaco de David solbre las muertés de Saúl y Jonathás», que son sea imitaciones de proferías, sea traducciones de salmus y vulgatas.

Los romances, por su parle, recogen los viejos temas de la tradición clásica. So nota claramente la influeneia de T'cócrito, Anacreonte y Roussean. Señalemos sin embargo el último ronance del volumen, « $\Lambda$ mi tumba», que acaba así:

¿Qué es el hombre, el rey del mundo,

Sino flor caduca de heno,

Huésped de un dia que pasa,

Pompa en linfa a faz de viento? ${ }^{27}$

\section{III-4. Idilios y cantatas}

Desde *Embelesos de la primavera: a mis anigos", idilio que abre la colección de las poesías manuscritas del magistrado aragonés, cualquier enamorado de las letras helénicas se da cuenta de que estamos de lleno en la inmía-

26 Lo dice el misn vate en el mss. 7851.

${ }^{27}$ Mss, 7851, f. $51 \mathrm{v}$. 
ción del cantor de Teos. El personaje poemático toma como pretexto la llegada de la primavera para aconsejar a sus amigos alegría, amores y borracheras. Digamos, para abreviar, que los idilios de Crespo beben en la musa teya. Lo mismo diremos de las cantatas donde todo son los amores voluptuosos del mundo de Anacreonte.

El lenguaje poético cambia de un poema a otro según el motivo desarrollado.

\section{III-5. Epistolas}

En el Siglo Ilustrado, en toda Europa, los géneros más populares eran los que se basaban en las cartas, vehículo de conversación entre amigos alejados. La correspondance littéraire del barón Von Grim mantuvo informados a los soberanos de toda Europa sobre las últimas noticias. Fue enviada a Federico de Prusia, Catalina de Rusia, Gustavo de Suecia, Estanislao-Augusto de Polonia, a los duques de Sajonia Gotha, a los de Toscana y a otras cortes reales. En el órgano de la crítica literaria y musical más vivo de su tiempo en Francia. También se publicaron en él las críticas de Diderot sobre el arte, de modo que los lectores lejanos podían informarse sobre la pintura francesa y orientar según ella sus compras de cuadros.

La literatura epistolar, pues, fue un instrumento de divulgación del espíritu ilustrado en toda Europa. Sebold ${ }^{28}$ afirma que hasta la crítica de la década de 1760 era epistolar. La correspondancia servía también para tratar de temas literarios o personales entre amigos alejados. Muchos escritores de renombre se ejercitaron en el género epistolar. Citemos tan sólo a Cadalso, Rousseau, Goethe. Montesquieu, Meléndez Valdés. ${ }^{29}$

Este es, pues, el marco dentro del cual se mueve la literatura española del XVIII, y consiguientemente, la de Rafael José de Crespo, quien, en el manuscrito que conserva la Biblioteca Nacional, nos dejó 4 epístolas en verso. Tratan de diferentes temas.

La «Epístola a Evandro aconsejándole el estudio de las matemáticas» es una verdadera apología de las ciencias, de los científicos mundialmente famosos (Platón, Newton, Descartes, Arquímedes, Galileo) y de los adelantos de la

${ }_{2 \mathrm{~B}}$ R. P. SEBOLD, Cadalso: el primer ramántico aeuropeo de España, Madrid, Gredos, 1974, pág. 36.

${ }_{29}$ Para mayor información, véase Mbol NANG, ob. cit., II, págs. 1.025-1.035. 
ciencia. Esa poesía de versos endecasílahos con la misma rima e-o es una fulgurante declaración de guerra a la ignorancia. ${ }^{30} \mathrm{La}$ *Epístola a Don*** en 1831» es una profunda meditación filosófica sobre el hombre, el crimen, la muerte. La «Epístola a don Aparici, poeta valenciano de 20 años; remitiéndole la traducción de la poética de Horacio hace la Apología de Apolo y de la poesía. Grespo recomienda a los jóvenes vates a Horacio, "Aquel, que da leyes y el ejemplo», La última epístola de la serie, "Roma en sus Vicisitudes», escrita en rigurosos tercetos dantescos, imita paso a paso a Juvenal, y Passe aupeigne fin la historia del imperio Romano. El tono violento, exclamativointerrogativo, condena enérgicamente a Roma, el modelo de la civilización occidental.

\section{III-6. Egloga. Cloe}

Las poesías manuscritas de Rafael José de Crespo se insertan en la convención pastoril que Nigel Glendinning ve en los Ocios de mi juventud de Cadalso, ${ }^{32}$ siguiendo el gusto de la época. Muchos poetas del siglo, aprovechando las mejores tradiciones clásicas y renacentistas, quisieron pasar de una vida real a una ideal. Por eso se pusieron máscaras y se llamaron pastores. Se entretuvieron con discursos bucólicos y platónicos. Se crearon una especie de mundo particular donde representar su vida.

La égloga, "Cloe», escrita en versos endecasilabos, recuerda a Garcilaso tanto por el tema como por el metro. Lia musa es Cloe, «La de más rojos labios que rubíes / La de las negras y lucientes cejas / A la par de milagro ninfa hermosa / Cúndida, afable, ticrna a maravilla, / Que fuera en liempo amor de cien pastores / Si Elisio, agraciadísimo mancebo, / Inédito, pero infiel, docto, mas cauto, / Cuanto gentil, voluble, y más que noble / Artero, a su rubor no armara redes*. ${ }^{33}$ Cloe se lamenta por la inconstancia del zagal Eliseo. El poema, sin embargo, acaba con Cloe esperanzada pero se sabe que nunca volverá el voluptuoso Eliseo. La égloga, de fuerte perfume renacentista, recuerda también la anacreóntica «La inconstancia» de Juan Meléndez Valdés.

30. El s. XVIII es un siglo que se autodenominó ilustrado. Se tuvo mucha líe en las ciencias y se luchó contra la ignorancia.

21 Mss. $7851,1.124$.

:2 Véane Nigel GlenDINNING, Vida y obra de Cadalso, Madrid, Gredus, 1962, pág. 10

Mss. 7851, f. 124 R. 


\section{La naturaleza como modelo de perfección}

La naturaleza fue considerada en el XVIII como modelo de perfección. Las artes imitativas, pues, deberían acercarse a ella. Luzán ${ }^{34}$ consideraba el verso como un simple instrumento de que se sirve la poesía para imitar la naturaleza. Así pues, la poesía se confunde con la pintura y la escultura, otras artes que imitan la naturaleza. Los poetas neoclásicos ven en ella una inagotable fuente de inspiración. Las mismas ideas están en Crespo quien dice en su Poética:

Elije a la natura por maestro,

Y la ideal belleza en ella aprende,

Que de individuos forma artista diestro ${ }^{35}$

La naturaleza de los versos de Crespo es la idealizada. Se trata generalmente de una visión gozosa que simboliza el triunfo del sol, de la vegetación y de las flores, de los arroyos, y sobre todo del dulce licor de Baco. El olor de las frutas maduras embriaga el alma así como los variados colores. Fis el mundo de ninfas, aves, verdes prados, aguas cristalinas, alegres pastores y pastoras.

En la égloga «Cloe», se dibuja toda la tradición de la poesía bucólica, tanto de la antigüedad clásica como del Renacimiento; y el nuevo sentimiento que parte de los vates dieciochescos.

Aparccen los antiguos tópicos del locus amoenus. En la sensibilidad del campo el poeta encuentra sosiego observando el viento que susurra entre las hojas, el arroyuelo de Aragón que pasa besando las hierbas de la ribera, los amores gozosos o celosos, mientras el sol va derramando sus rayos dorados en el valle tranquilo que pastores y pastoras, zagales y zagalas comparte con Cupido y Venus, bajo la bendición de Baco.

El deseo de dar brillo a la naturaleza conduce a un magnífico juego de luces y colores. El poeta da la variedad de flores como nota general para un lugar, con adjetivos que traducen la abundancia, el color, otras notas. La naturaleza se muestra, las más de las veces, radiante, bella y agradable. Con unas pinceladas dignas del discípulo de Apeles, don Rafael José de Crespo nos presenta una naturaleza que hace mucho recordar a los neoclásicos. Como ante un cuadro, el ojo del lector sigue la pluma de Crespo y va descubriendo colores brillantes o cualquier vasija decorada con escenas campestres. La úmica enumeración de flores da una sensación integral del agrado de los sentidos. En cuanto a

34 Ignacio DE LUZAN, Poética, ed. de Russell P. Sebold, Barcelona, Labor, 1977, pág. 159.

93 Rafael José DE CRESPO, Poética, ed, cit, Canto I, pág. 7. 
su diversidad, las cualidades simples de color que halagan la retina y en cuyo contraste o mezcla se recrea la sensibilidad artística son generalmente las de la blancura (lirio, azucenas) y el rojo (rosas, labios). Pero la gama variada de cromatismo es bastante variada. En muchos casos estamos ante el verde, oro-rubio, amarillo y otros colores. Ein este sentido los valles forman una inmensa guirnalda de flores multicolores como un arco iris:

...acantos

Junquillos, ciclamores,

Mosquetas, amarantos

$Y$ otras preciadas flores,

Cuenta bien: diez violas,

Almoradujes ciento

Veinte y dos amapolas,

Mas gualdas que en mar olas,

Eintumerables cuento

De mirtos y claveles

carísimos al viento.

No olvides mirabeles,

Naïs, ni rosas bellas

Cuantas en cielo estrellas.

$Y$ si ya te cansares

De contar azahares

Pacibles a doncellas,

Siquiera los cantuesos

Bien digno son de besos. ${ }^{31}$

La enumeración ayuda a ir descubriendo paso a paso, lenta, detenidamente, la belleza y la variedad de perfumes de los diferentes componentes de esa bellísima naturaleza rica en aromá y colorido. Toda esta belleza está enfatizada no sólo por la enumeración, sino también por la adjetivación, los símiles, el hipérbaton, y sobre todo, por el hipérbole ("más gualdas que en mar olas»; Almoradujes ciento»; rosas bellas / Cuantás en cielo estrellas»).

El mundo de las poesias de Crespo es generalmente un mundo artificial. Todo es convención literaria. Muchos versos, empapados de sensualismo, recuerdan a Anacreonte, Teócrito, Gésner, Thomson, Saint Lambert, Jean Jacques Rousseau.

Jw Mss. 7851, f. 44. 


\section{Didactismo}

Evoluciona el pensamiento poético del vate aragonés. Al contrario de los idilios, letrillas y anacreónticas que quieren esencialmente deleitar y distraer al lector con dulces y sonoros versos, Las Fábulas morales y literarias piensan ser fundamentalmente educadoras.

Cabría recordar que en el XVIII se cultivó intensamente una poesía de carácter didáctico o pedagógico cuya meta era educar, corregir las malas costumbres, formar al hombre, difundir ideas para el bien común. La confianza de ese siglo de educadores en la utilidad de la enseñanza es ciega. La poesía del Siglo Ilustrado no podía ser sino pedagógica, para ser consecuente consigo misma y con su tiempo. El hombre del Setecientos estaba demasiado ocupado con el aluvión de problemas que se había propuesto resolver, demasiado orgulloso de su razón y de su eficacia, para estimar merecedoras de su atención las vacías trivialidades que venían manoseando a los poetas. El tema de la educación, pues, es una de las preocupaciones prioritarias del siglo. El didactismo aborda todos los puntos de la educación. ${ }^{37}$ Don Nicolás Fernández de Moratín, incluso, escribirá un Arte de las putas, pensando que igual que se enseñaba un xarte poética”, se podía escribir un arte que adiestrara sobre tal oficio. Su intención es adiestrar a los jóvenes para que puedan satisfacer lo que él hlama "la necesidad» amorosa, de forma económica y sin perjuicio de su salud. ${ }^{38}$

La educación se dirigía ante todo al mundo de los niños. Por eso Samaniego publicó sus Fábulas en verso castellano en 1781. Después siguieron Tomás de Iriarte con sus Fábulas literarias de 1782, Vicente Rodríguez de Arellano, y otros poetas más.

En este mismo orden de ideas, Rafael José de Crespo escribió en tierna edad $^{39}$ sus Fábulas morales y literarias -96 en total-con el propósito de formar al hombre moral, civil y literario, rectificar sus ideas, desarrollar su facultad observadora y adelantar progresivamente su razón. Las fábulas -dice- siembran en su imaginación (se trata del niño) las semillas de la filosofía práctica, o sea, de la ciencia de las costumbres, desenvuelan mil pensa-

97 Véase Mbol NANG, Ob. cit., I, págs. 156-158.

yв Véase Manuel FERNÁNDEZ NIETO, Art. cit., anteriomente.

39 Afirma haberlas escrito en tierna edad (Fábulas morales y literarias, ed. cit., p. 4). Si se considera que en 1808 ya tiene el escritor 21 años, podemos deducir que las escribió a finales del XVIII. 
mientos profundos, y mejoran las nociones viciadas. Advierte el fabulista aragonés:

Yo escribo para el pueblo y los muchachos;

$Y$ a vueltas de la chanza

Les presento en mis versos la enseñanza.

Los lobos, las ovejas y los muchachos,

Los gatos y los ratones,

Mis héroes vé aquí, vé mis d'arones:

$E$ intento perpetuar en la memoria

Sus discursos, sus hechos y su historia.

Mas útiles lecciones

inspiran la oveja y el cordero

Que los insignes héroes de Homero. ${ }^{j 0}$

Es consciente Crespo de que escribe para «el pueblo - o sea los adultos- y los muchachos». Por eso escribe en «A quien leyere que las fábulas «son también provechosas a los adultos porque dan lecciones de buena moral bajo el velo agraciado de la alegoría, insinúan la verdad sin ofender, describen la fisonomía del vicio sin sal corrosiva, y censuran las bagatelas, los abusos y los viciosos hábitos sin hiel, ${ }^{+1}$

Movido por ese impulso educador y moralizador, quiso reescribir el Edipo, corrigiendo los vicios que aparecen en la obra de Sófocles. El magistrado no ve con buenos ojos que se indulte a alguien que mató a su padre y se casó con su madre bajo el pretexto de fatalismo. El incesto y el parricidio, piensa Crespo, son algo que hay que condenar enérgicamente porque se trata de crímenes, por involuntarios que sean, que ninguna razón excusa. El fatalismo para él no fue enseñanza de legisladores, magistrados, sacerdotes, ni creencia de pueblos, sino una absurda teoría de los sofistas. Desgraciadamente, no pudo llevar a cabo su empresa: sólo escribió 34 versos de la primera escena del Acto I. Luego enfermó y murió en 1842.

Digamos, para abreviar, que casi todos los preceptistas del Setecientos, empezando por Ignacio de Luzán, habían proclamado la finalidad moralizadora de la poesía. De ahí la abundante producción didáctica y didascálica que hubo en las letras de la España ilustrada.

40 Rafael Josê DE CRESPO, Fábuless morales $y$ literartros, ed. cit, págs. 14-15.

"Vid. aA quien leyerex en Fóbulas morales y literarias, ed. cit., s. p. 
La necesidad de felicitar a un amigo recién nombrado a un alto cargo, de elogiar las artes, las instituciones públicas, las ciencias, las virtudes de los alumnos o de las personalidades políticas, religiosas, o artísticas, llevó en el XVIII al cultivo de lo que la crítica llamó la poesía de circunstancias.

Esa es esencialmente una poesía de conmemoraciones. A ello hay que añadir toda la abundancia de elegías escritas con motivo de la muerte de familiares o de amigos. Ahora bien, si en ello la inspiración no está del todo ausente, el tema le viene impuesto al vate desde arriba, y son generalmente piezas de poco valor estético.

Señalemos, como poesías de circunstancia de Crespo, las odas «Por la feliz exaltación al trono del rey señor nuestro D. Fernando VII» $\mathrm{y}$ «A las ruinas de Zaragoza». Entraría también aquí el canto épico «La Hernandíada».

\section{Romanticismo?}

La «Epístola a Evandro aconsejándole el estudio de las matemáticas» es de 1836, o sea, ya muy entrado el siglo XIX. Crespo, pues, escribe en las mismas décadas cuando en Europa era de moda el Romanticismo. Sin embargo, una lectura atenta de sus escritos no deja ver elementos románticos. Si el Romanticismo caracteriza el XIX, don Rafael José de Grespo prolonga en él la forma mentis del Siglo de las Luces. Por ello, digo, es un epígono del XVIII.

Ya entre 1770 y 1790 se desarrolla en España lo que la crítica llamó el prerromanticismo. Se generaliza la literatura de la noche y de los sepulcros. ${ }^{42}$ Esa poesía lacrimosa conoce un esplendor particular en Inglaterra con The Night Thougths del Dr. Young y desde el Reino Unido se generaliza por todo el continente europeo. En España hubo, incluso, anacreónticas necrológicas. ${ }^{43}$ En

+2 Panl VAN TIEGHEM, La poésie de la nuit et des tombeaux en Europe au XVIII siècle, Génève, Statkine Reprints, 1970.

+3adalso escribió 3 anacreónticas necrológicas con motivo de la muerte de la hermosa María Ignacia lbáñez. Véase Ocios de mi juventud o poesias líricas de D. Josef Vázquez, en continuación de Los eruditos a la Violeta, Madrid, por Don Isidoro Hernández Pacheco, año LXXXI, págs. 91 y 95, respectivamente. Véase también, BAE, LXI págs. 275 b. Se trata de los siguientes poemas: «A la muerte de Philiz», «Lamentos con Motivo de la muerte de Philis», «Sobre las noches lúgubres que he compuesto con motivo de la muerte de Philis, imitando el estilo y los pensamientos de tristeza de las que compuso en Inglés el doctor Young». Sor Gertrudis de Hore también tiene anacreónticas fúnebres. 
cualquier obra se podía percibir el "Mal universal», el mal du siècle. El lenguaje poético se hace lacrimoso, quebrado con palabras graves y tristes, abundancia de exclamaciones e interrogaciones. El vate se deshace de estorbos retóricos para llegar a una expresión directa de sentimientos. Estamos ante una poesía sensible que busca un lenguaje comunicativo.

Si volvemos la vista al pasado, observamos que muchos escritores españoles anteriores, que conocía muy bien y leyó Rafael José de Crespo, siguiendo los vientos que soplaban desde el Reino Unido, son románticos, o por lo menos prerrománticos. R. P. Sebold ${ }^{4+}$ ya llamó a Cadalso primer romántico «enropeo» de España. Analizando las poesías del destierro del extremeño, Emilio Palacios Fernández se pregunta si Juan Meléndez Valdés no es romántico. ${ }^{45}$ La crítica concuerda en que Jovellanos es un escritor romántico. Curiosamente no se observa nada de ello en Rafael José de Crespo. Ya dijo:

Tú no apartes jamás de entre las manos,

Ojos innobles, día y noche atento

A los modelos griegos y romanos. ${ }^{\text {to }}$

Y esa es su poética. Se autodefine como un imitador de los griegos y romanos, o sea, un neoclásico. A veces se inquieta el vate, se enfada, pero nunca llega a la desesperación y tono lacrimoso de los románticos. Se queda en la meditación fílosófica de la Ilustración.

\section{Conclusión}

Don Rafael José de Crespo es el último de los poetas nacidos en las últimas décadas del Setecientos que prolonga en el XIX la lírica del Siglo Ilustrado. Es espiritualmente hijo del XVIII. Aunque sus últimos poemas sean de 1836, no se nota en él la menor influencia del romanticismo. La mayoría de los poema no están fechados y ello no deja ver claramente qué piezas fueron escritas en el XVIII y cuáles en el XIX. La letra del manuscrito 7851 conservado en la Biblioteca Nacional es del XVIII, como lo son también los metros, modelos, géneros, las preocupuciones e inquietudes de la Ilustración española, la confianza en las ciencias, en la razón y en la naturaleza.

*4 Vid. R. P. SEBOTD, aEl incesto, el suicidio y el primer rontanticisma", en Hispanir Revieu, XLI, 1973; Cadalso: el primer romántico seuropeon de España, Madrid, Credos, 1974.

47. Emilio PALACIOS FERNANDEZ, Introducción a Juan Meléndez Valdés, Poesíes, Bilbao, Allhambra, 1979, pág. 117.

* Rafae] José DE CRESPO, Pó́sica, ed, cit., pág. 7 . 
A veces Crespo se hace satírico en sus poesías ligeras, moralizador en las fábulas.

Don Rafael José de Crespo, que siempre ha considerado la poesía como diversión, no deja sin embargo de preocuparse por lo estético, la perfección formal. Quiere seguir las reglas de arte de Luzán, el preceptista aragonés del Siglo de las Luces. Busca claridad y sencillez en la expresión, y por ello condena los arcaísmos. El estilo del poeta del Alfajarín se acerca mucho al de los neoclásicos, especialmente al del coronel gaditano José Cadalso y al de los hermanos Canga-Argüelles. 